\title{
Forças verticais e de atrito em silos cilíndricos com fundo plano
}

\author{
José P. Lopes Neto', José W. B. do Nascimento² \& Marivone Z. Fank ${ }^{3}$ \\ ${ }^{1}$ UAEA/UFCG. Campina Grande, PB. Fone: (83) 2101-1490. E-mail: lopesneto@deag.ufcg.edu.br (Autor correspondente) \\ ${ }^{2}$ UAEA/UFCG. Fone: (83) 2101-1482. E-mail: wallace@deag.ufcg.edu.br \\ ${ }^{3}$ UAEA/UFCG. Fone: (83) 2101-1482. E-mail: marizanella@gmail.com
}

\section{Palavras-chave:}

estruturas de armazenamento instrumentação

carregamento

descarregamento

\begin{abstract}
R E S U M O
A predição exata das forças que atuam no corpo de um silo é um dos principais problemas, no que tange ao quesito dimensionamento dessas estruturas. Com o objetivo de mensurar as forças atuantes no fundo e nas paredes dos silos durante o processo de descarregamento foram instrumentados, por meio de células de carga e células de pressão, a parede e o fundo de um silo piloto vertical cilíndrico com fundo plano. As leituras das células foram realizadas por sistema automático de aquisição de dados durante o carregamento e o descarregamento de areia seca. $\mathrm{O}$ silo foi carregado concentricamente e descarregado concêntrica e excentricamente, a partir de duas excentricidades. O experimento ocorreu no período de janeiro a abril de 2008, no Laboratório de Construções Rurais e Ambiência da Universidade Federal de Campina Grande, PB. Os valores experimentais foram confrontados com os prescritos pelas normas Eurocode 1, ISO 11697, AS 3774 e DIN 1055. Conclui-se, então, que os valores teóricos de força vertical propostos pelas normas foram superestimados em relação aos obtidos experimentalmente para a maioria das formas de descarregamento. Para a força de atrito nas paredes as normas produziram resultados compatíveis com os obtidos experimentalmente.
\end{abstract}

Key words: storage structures instrumentation loading unloading

\section{Vertical and friction forces in flat-bottom cylindrical silos}

\begin{abstract}
A B S T R A C T
The exact prediction of the forces that act on the vertical walls of silo is major problem when it comes to the question of design of these structures. In order to measure the forces acting on the bottom and vertical walls of the silo, the vertical wall and the bottom of a pilot vertical flat-bottom cylindrical silo was instrumented through load cells and pressure cells. The cell readings were performed by automatic data acquisition during loading and unloading of dry sand. The silo was concentrically loaded and concentric and eccentrically unloaded from two eccentricities. The experiment took place during the period from January to April 2008 at the Environment and Rural Construction Laboratory of Federal University of Campina Grande, Paraíba. The experimental values were compared with the standards Eurocode 1, ISO 11697, AS 3774 and DIN 1055. It can be concluded that theoretical values of vertical force were overestimated when compared with experimental results for majority of unloading methods. For friction forces on silo walls, the values from standards were compatible with the experimental results.
\end{abstract}

\section{INTRODUÇÃo}

As ações em silos verticais se dividem em forças verticais em virtude da ação gravitacional sobre o produto armazenado as quais são direcionadas para o fundo da estrutura, forças horizontais suportadas pelas paredes laterais em razão da contenção lateral imposta ao produto e forças verticais de atrito que são absorvidas pelas contenções laterais em razão do atrito grão-parede. Quanto maior for a rugosidade da superfície da parede e/ou do grão maior também será a força de atrito absorvida por ela.

Sadowski \& Rotter (2011) afirmam que em silos cilíndricos com descarga concêntrica a compressão axial na parede do silo é originada pela fricção entre a parede e o produto armazenado cuja tensão de compressão axial resultante é acumulativa com a profundidade de modo que o risco de deformação é substancialmente aumentado na direção da base do silo.
Vários métodos estruturais de previsão das ações em silos vêm sendo aprimorados; no entanto, apesar dos avanços realizados muitos dos problemas observados na prática persistem em razão de que o comportamento do material granular e as pressões exercidas sobre as paredes do silo ainda não são completamente compreendidos (Dogangun et al., 2009).

Marques Neto \& Silva (2011) ressaltam que as dificuldades construtivas carecem de um estudo mais aprofundado das ações que agem na estrutura provenientes do produto ensilado para que soluções mais simples possam ser alcançadas. Ramírez et al. (2010) também afirmam que as falhas estruturais comumente vistas na indústria mostram a falta de conhecimento sobre o comportamento do sólido a granel em silos.

O correto dimensionamento das ações que atuam sobre as paredes e o fundo do silo é essencial e, para se projetar um silo com segurança e eficiência, é necessário que o projetista 
conheça as máximas pressões possíveis de atuar sobre as paredes do silo durante sua vida operacional (Palma \& Calil Júnior, 2008). Apesar disto, tão somente o conhecimento de seus valores máximos não é suficiente para garantir um projeto bem desenvolvido, uma vez que imperfeições das paredes e excentricidade de carga e descarga podem ocasionar o desenvolvimento de ações não previstas e desuniformes ao longo da profundidade da parede dos silos o que, no caso das forças de atrito, pode gerar momentos fletores diametrais e flambagem localizada.

Ao mensurar as ações ocasionadas por grãos de trigo em um silo cilíndrico de paredes lisas com relação altura/diâmetro igual a 2, Ruiz et al. (2012) verificaram que as pressões foram máximas nos primeiros segundos da descarga atingindo diferenças acima de $20 \%$ entre a fase estática e a dinâmica. Wójcika et al. (2012) também constataram, estudando as forças existentes em um silo com contra-tremonha e relação altura/diâmetro igual a 3, os maiores valores no início do descarregamento, da ordem de $23 \mathrm{kPa}$ e diferença para as pressões estáticas de $21,7 \%$.

$\mathrm{Na}$ tentativa de fornecer informações importantes para compreensão do comportamento das forças em silos verticais, este trabalho propôs mensurar experimentalmente as forças verticais e de atrito em um silo piloto através de múltiplas descargas, realizando análise comparativa com os valores prescritos pelas principais normas vigentes.

\section{Material e Métodos}

Com vista à realização da pesquisa, foi projetado, construído, instrumentado e ensaiado um silo cilíndrico metálico com paredes lisas e fundo plano; o experimento ocorreu na Universidade Federal de Campina Grande (UFCG) sendo as análises realizadas de janeiro a abril de 2008.

O corpo do silo cujas paredes foram confeccionadas com chapas metálicas de 1,98 $\mathrm{mm}$ de espessura foi dividido em dois anéis, denominados anel I, o anel inferior e anel II, o superior. Os aneis foram obtidos pela união de chapas metálicas com dimensões de 2,00 x 1,00 m (largura x altura); para o anel I foram utilizadas duas chapas metálicas resultando em um cilindro de $1,00 \mathrm{~m}$ de profundidade, $1,24 \mathrm{~m}$ de diâmetro e $1,20 \mathrm{~m}^{3}$ de volume e para o anel II foram utilizadas quatro chapas metálicas resultando em um cilindro de 2,00 m de profundidade, $1,24 \mathrm{~m}$ de diâmetro e $2,4 \mathrm{~m}^{3}$ de volume.

O fundo plano do silo foi composto de uma chapa de madeira compensada com espessura de $15 \mathrm{~mm}$, revestimento superior metálico e enrijecida por uma estrutura metálica em formato hexagonal na parte inferior e apresentava cinco orifícios de descarga, um concêntrico e quatro excêntricos, denominados D1, D2, D3, D4 e D5.

Para garantir que as principais partes constituintes do silo (fundo plano, anel I e anel II) trabalhassem de forma independente foi estabelecido, entre elas, um vão livre de aproximadamente $10 \mathrm{~mm}$; assim, o anel I foi sobreposto ao fundo plano respeitando uma distância vertical de $10 \mathrm{~mm}$ enquanto o anel II foi sobreposto ao anel I do qual distava 10 $\mathrm{mm}$. Esta folga, que posteriormente foi selada com fita plástica adesiva, permitiu a medição e a análise da força de atrito no corpo do silo em duas profundidades diferentes, de forma independente e conjunta, assim como a obtenção das forças verticais no fundo do silo sem a interferência, transferência de cargas ou mesmo interações entre cargas verticais e de atrito.

Após a montagem de suas partes constituintes obteve-se um silo vertical cilíndrico com 1,24 m de diâmetro e 3,00 m de profundidade com capacidade total de armazenagem igual 3,6 $\mathrm{m}^{3}$ e relação H/D igual a 2,4 conforme indicado na Figura 1.

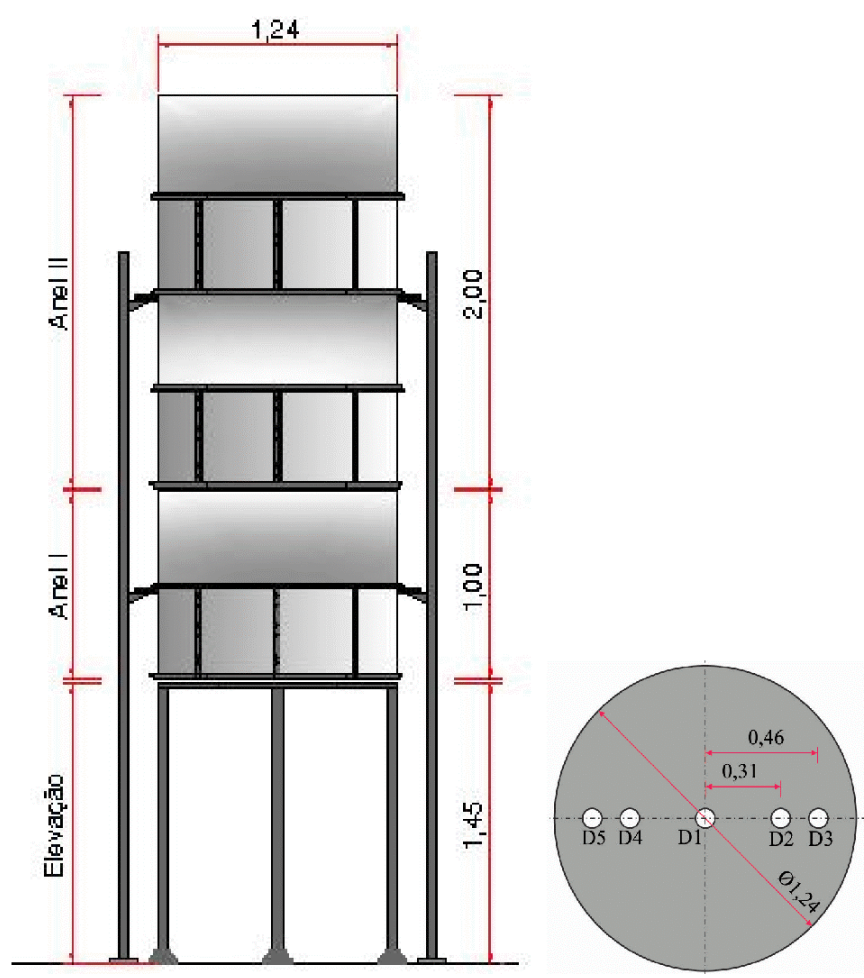

Figura 1. Silo-piloto e disposição dos orifícios no fundo plano

Utilizou-se, como produto armazenável, areia lavada por apresentar elevado peso específico aparente, entre 14 e 17 $\mathrm{kN} \mathrm{m}^{-3}$, uniformidade de partículas, facilidade de aquisição e por proporcionar elevadas cargas na estrutura assegurando, desta forma, que os dados obtidos pudessem ser considerados quantitativamente representativos dos esforços desenvolvidos; além disto, trata-se de um produto que, quando seco, possui um fluxo do tipo livre, sem obstruções, segregação de produto, compactação e outros problemas funcionais passíveis de impedir uma coleta adequada de informações.

Foram realizadas múltiplas descargas, concêntricas e excêntricas. Para a primeira, utilizou-se o orifício D1; para a descarga excêntrica a $75 \%$ foi utilizado o orifício D3, para a descarga múltipla a $50 \%$ foi utilizada uma combinação simultânea dos orifícios D2 e D4 enquanto que para a descarga múltipla a $75 \%$ a combinação utilizada foi a dos orifícios D3 e D5, as quais foram repetidas quatro vezes.

A instrumentação do corpo do silo para mensuração das forças de atrito se deu pela utilização de seis células de carga de capacidade igual a 5,4 kN fixadas aos aneis e conectadas às colunas do silo. Cada anel (anel I e anel II) foi instrumentado com 
três células de carga instaladas na altura de aproximadamente 1/2 da profundidade do respectivo anel e dispostas horizontalmente na distância, uma das outras, equivalente a $120^{\circ}$. Deste modo, cada sensor registraria a força de atrito para uma porção diametral das paredes nos dois aneis. A Figura 2 mostra a distribuição horizontal das células de carga no silo.

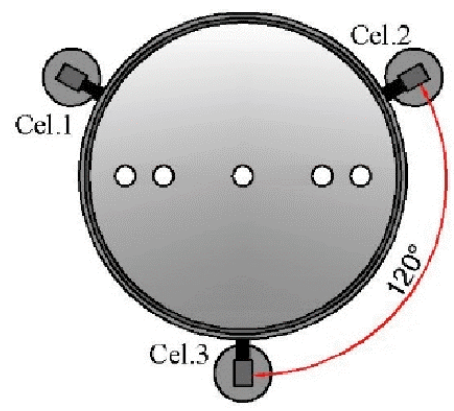

Figura 2. Posicionamento das células de carga (visão superior)

Os dados de força vertical foram tomados a partir dos resultados coletados nas células de pressão modelo Geokon instaladas na base de cada coluna que sustentava o fundo plano. Os valores de pressão vertical foram convertidos em força vertical multiplicando-se seu valor pela área útil da célula que, neste caso, era de 0,045 $\mathrm{m}^{2}$. Foi montado, em cada base, um conjunto de placas de madeira e borracha para permitir uma acomodação da estrutura e a melhor distribuição das cargas, conforme Figura 3.

Previamente à instrumentação do silo, cada sensor foi conectado a um sistema de aquisição de dados Modelo Spider $8600 \mathrm{~Hz}$ de fabricação da HBM. A calibração das células de carga foi aferida utilizando-se volumes conhecidos de água. A cada acréscimo de volume o sistema registrava uma variação de potencial elétrico até a obtenção de um quadro que expressasse uma relação confiável entre carga/variação elétrica para cada sensor.

Com vista à determinação das propriedades físicas do produto armazenado, neste caso da areia seca, foi utilizado o aparelho de cisalhamento de translação conhecido internacionalmente por Jenike Shear, em que foram determinados o peso específico em função da consolidação $(\gamma)$, o ângulo de atrito interno $(\varnothing)$; o efetivo ângulo de atrito interno $(\delta)$ e o ângulo de atrito entre o produto armazenado e o material da parede do silo $\left(\varnothing_{\mathrm{w}}\right)$.

A relação teórica entre as pressões horizontais e verticais (fator $\mathrm{k}$ ) foi determinada de forma indireta através da análise

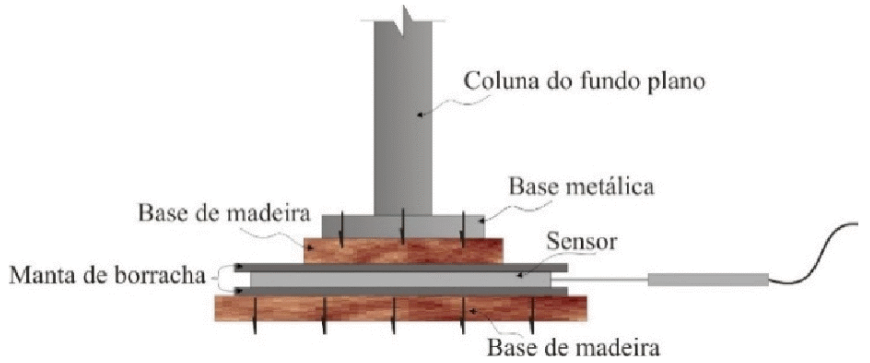

Figura 3. Conjunto montado para instalação das células de pressão das forças cisalhantes e das tensões de Mohr obtidas nos ensaios de cisalhamento com o aparelho de Jenike. Os valores obtidos experimentalmente para o fator $\mathrm{k}$ foram confrontados com os valores encontrados por meio das Eqs. 1, 2 e 3, propostas por Jaky (1948), Aoki (1978) e Walker (1966), respectivamente.

$$
\begin{gathered}
\mathrm{k}=\frac{(1-\sin \delta)\left(1+\frac{2}{3} \sin \delta\right)}{1+\sin \delta} \\
\mathrm{k}=\left[1+2 \operatorname{tg}^{2} \delta+\frac{4 \sqrt{1+\operatorname{tg}^{2} \delta}}{3 \mu^{2}}\left\{\operatorname{tg}^{3} \delta-\left(\operatorname{tg}^{2} \delta-\mu^{2}\right)^{\frac{3}{2}}\right\}\right]^{-1} \\
\mathrm{k}=\frac{1+\left(\sin ^{2} \delta\right)-2 \sqrt{\sin ^{2} \delta-\mu^{2} \cos ^{2} \delta}}{4 \mu^{2}+\cos ^{2} \delta}
\end{gathered}
$$

em que:

$\delta \quad-$ efetivo ângulo de atrito interno, ${ }^{\circ}$

$\mu \quad$ - coeficiente de atrito

$\emptyset_{\mathrm{w}} \quad$ - ângulo de atrito com a parede, ${ }^{\circ}$

A força total de atrito na parede, considerada como sendo a somatória das forças obtidas nos dois aneis e a força vertical no fundo do silo obtidas experimentalmente, foram comparadas com valores encontrados teoricamente por meio das prescrições contidas nas normas internacionais AS 3774 (1996), DIN 1055 (1987), ISO 11697 (1995) e Eurocode 1 (2006).

\section{Resultados e Discussões}

$\mathrm{Na}$ Tabela 1 constam os valores obtidos nos ensaios para o peso específico consolidado, ângulo de atrito interno, efetivo ângulo de atrito interno e ângulo de atrito com a parede e os preconizados por normas internacionais para areia utilizada. Pode-se destacar que a areia lavada apresenta variação de 5 a $23 \%$ entre os limites de suas propriedades. Quanto aos valores normatizados observa-se grande consonância com os dados experimentais, o que confirma a credibilidade das propriedades descritas anteriormente.

Para o fator k os limites inferiores e superiores encontrados experimentalmente durante o descarregamento foram de 0,3 e 0,35, respectivamente, podendo ser observados na Figura 4.

Os valores mais próximos foram obtidos sequencialmente para as teorias Jaky (1948), Aoki (1978) e Walker (1966). Pela equação de Jaky (1948) os valores preconizados foram inferiores até $17 \%$ para ambos os limites (inferiores e superiores); entretanto, foram os mais aproximados dentre todas as equações de previsão utilizadas.

A teoria de Walker (1966) assume que o produto ensilado já se encontra em ruptura e, simultaneamente, deslizando ao longo de uma parede rugosa. O fato da teoria de Jaky (1948) produzir valores mais próximos aos experimentais e se basear na hipótese da existência de uma relação para o fator $k$ para o caso do produto em repouso (estado elástico) e parede lisa e rígida, 
Tabela 1. Variações das principais propriedades de fluxo obtidas para a areia

\begin{tabular}{|c|c|c|c|c|c|c|c|c|}
\hline Areia & \multicolumn{2}{|c|}{$\begin{array}{c}\text { Peso específico consolidado } \\
\gamma\left(\mathrm{kN} \mathrm{m}^{-3}\right)\end{array}$} & \multicolumn{2}{|c|}{$\begin{array}{l}\text { Ângulo de atrito } \\
\text { interno (Ø) }\end{array}$} & \multicolumn{2}{|c|}{$\begin{array}{c}\text { Efetivo ângulo de atrito } \\
\text { interno }(\delta)\end{array}$} & \multicolumn{2}{|c|}{$\begin{array}{c}\text { Ângulo de atrito com a } \\
\text { parede }\left(\emptyset_{\mathrm{w}}\right)\end{array}$} \\
\hline Limites & 16,5 & 17,0 & $32,2^{0}$ & $39,5^{0}$ & $36,7^{\circ}$ & $40,9^{\circ}$ & $26,2^{\circ}$ & $27,3^{\circ}$ \\
\hline \multicolumn{9}{|c|}{ Normas } \\
\hline AS 3774 & 15,0 & 17,0 & $\star \star$ & $\star \star$ & $35,0^{0}$ & $40,0^{\circ}$ & $30,0^{0}$ & $35,0^{\circ}$ \\
\hline EN1991-4 & 14,0 & 16,0 & $33,0^{\circ}$ & $39,2^{\circ}$ & ** & ** & $26,2^{0}$ & $33,5^{0}$ \\
\hline
\end{tabular}

** Valores não informados pelas normas

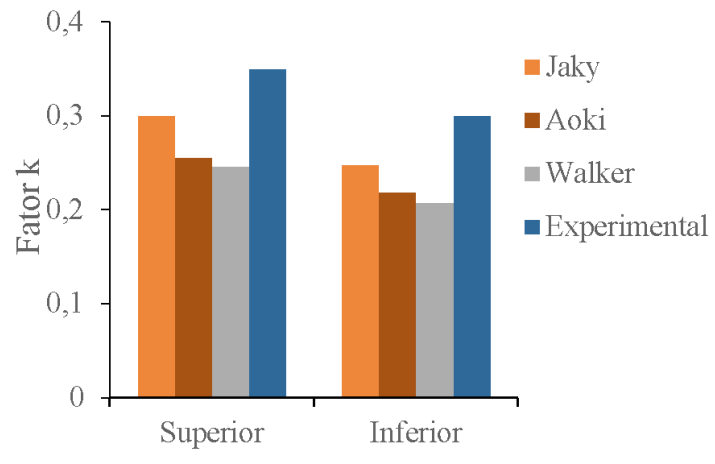

Figura 4. Variação do fator $k$

o que é inverso na teoria de Walker (1966), reforça a ideia da existência de três estados de tensão associados ao fator $\mathrm{k}$, um estado ativo, um passivo e outro em repouso. Os dois primeiros estados resultam do movimento da parede para fora e em direção ao produto armazenado, respectivamente, enquanto o terceiro aconteceria quando uma estrutura de retenção inflexível não permitisse a deformação lateral na periferia do produto.

Nascimento \& Calil Júnior (2009) obtiveram, ao medir o fator $\mathrm{k}$ para o carregamento de um silo cilíndrico metálico de paredes lisas, valores médios iguais a $0,45,0,32$ e 0,29 para grãos de milho, soja e ração avícola, respectivamente, enquanto que Ruiz et al. (2012) encontraram valores médios para $k$ de 0,34 no carregamento e 0,38 para o descarregamento de grãos de trigo em um silo metálico com paredes lisas e relação altura/ diâmetro igual a 2. Apesar dos valores entre essas pesquisas se apresentarem dentro de uma mesma faixa de variação, é importante observar que o fator $k$ não é constante ao longo da profundidade do silo e que distorções podem surgir quando analisados apenas os valores médios.

$\mathrm{Na}$ maioria das teorias sobre as relações das pressões laterais o fator k é determinado apenas com o conhecimento do efetivo ângulo de atrito interno sendo o ângulo de atrito com a parede considerado em apenas algumas formulações identificando que ainda existe muita incerteza para o cálculo deste parâmetro.

As forças verticais e de atrito obtidas no fundo do silo nas descargas são apresentadas na Figura 5.

Na Figura 5A nota-se que os valores preditos pela DIN 1055 (1987) se encaixam perfeitamente nos experimentais para a profundidade de $1,00 \mathrm{~m}$; contudo, sua predição passa a ser insatisfatória quando comparada com a maior profundidade do silo. De forma geral, os valores recomendados pela AS 3774 (1996) e ISO 11697 (1995) foram os mais adequados para o descarregamento concêntrico por ficarem, em média, 15\% acima dos encontrados de forma experimental.

De acordo com a Figura 5B, na qual constam os valores da força vertical medida no fundo do silo para a descarga excêntrica a $75 \%$, ocorreu aumento na tendência de ajuste entre os valores experimentais e os recomendados pela DIN 1055 (1987), ficando as demais normas ainda acima dos valores experimentais. Pela análise dos pontos teóricos é possível observar que os coeficientes de sobrecarga adotados pelas demais normas são muito próximos uns dos outros resultando em curvas bastante semelhantes.

Nas Figuras 5C e 5D são apresentados os valores das forças verticais para as descargas múltiplas de $50 \%$ e $75 \%$, respectivamente. A norma DIN 1055 (1987) apresentou-se adequada por praticamente se igualar aos valores encontrados nos ensaios. Esse resultado se deve ao fato de o coeficiente de sobrecarga adotado por essa norma diferir em apenas $2 \%$ do encontrado experimentalmente. Para as demais normas os valores teóricos ficaram em média 34 e $23 \%$ acima dos experimentais para essas descargas.

Nas Figuras 5E, 5F, 5G e 5H se encontram as curvas representativas da força de atrito na parede do silo nas profunidades de 1,2 e $3 \mathrm{~m}$ durante o descarregamento concêntrico, excêntrico a 70\% e nas descargas múltiplas a 50 e $75 \%$, respectivamente. Na Figura 5 se destaca a boa aproximação das normas Eurocode 1 (2006) e ISO 11697 (1995) para a profundidade de $2 \mathrm{~m}$ e das normas DIN 1055 (1987) AS 3774 (1996) para a profundidade $3 \mathrm{~m}$.

As quatro normas utilizadas como comparativo se baseiam nas deduções de Janssen para a predição da pressão estática em silos. Como ponto de diferenciação cada norma costuma adotar diferentes coeficientes de multiplicação às pressões de carregamento para obtenção dos valores de descarga o que, inevitavelmente, tende a gerar diferentes resultados de pressão para o mesmo silo.

Ao analisar as forças em um silo cilíndrico com relação a altura/diâmetro igual a 2, Couto et al. (2013), não encontraram a mesma aproximação aos dados experimentais para a norma Eurocode 1 (2006) destacando que esta norma superestimou os resultados, em todo o experimento. Ao mensurar as pressões em um silo cilíndrico esbelto de paredes lisas, Cheung \& Calil Júnior (2009) concluíram que as forças de descarga podem ser perfeitamente representadas por meio de coeficientes de sobrecarga adicionados às forças de carregamento. Nesta 
A.

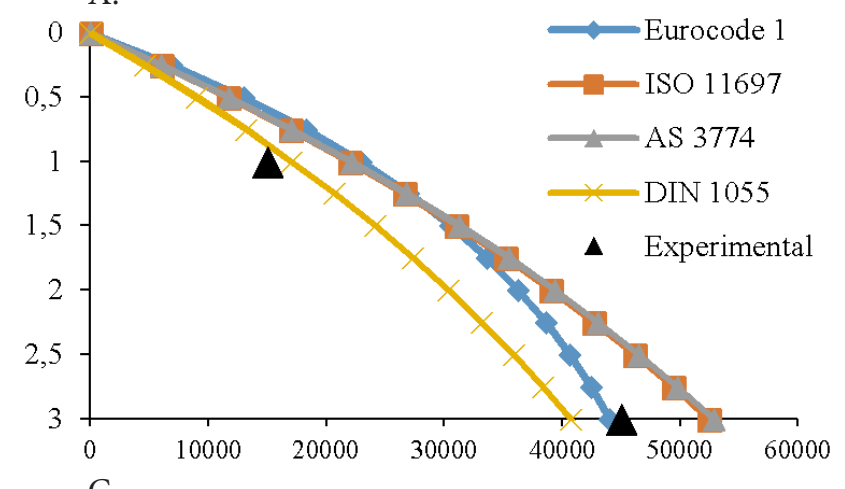

C.

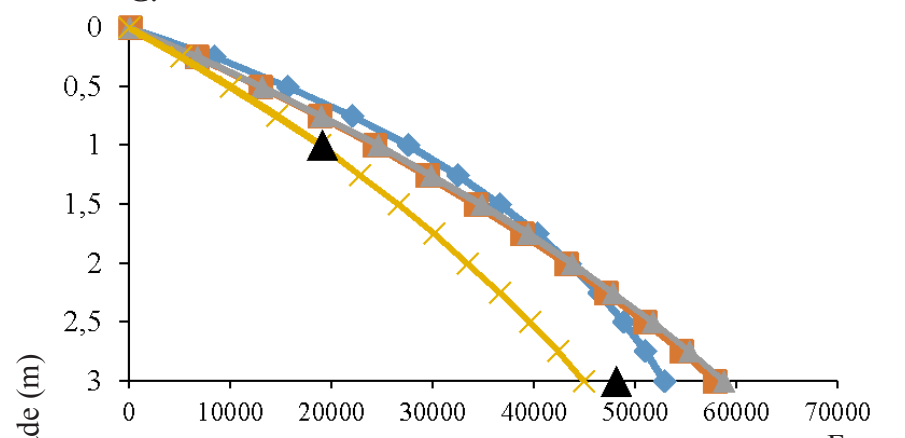

E.

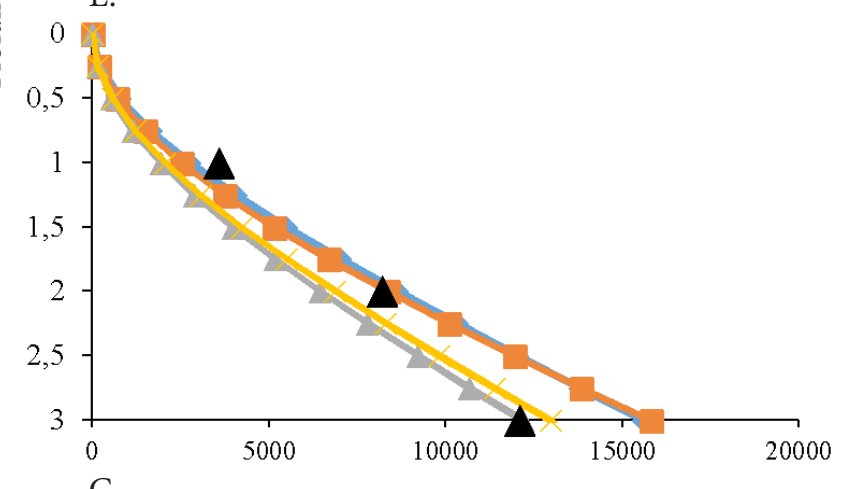

G.

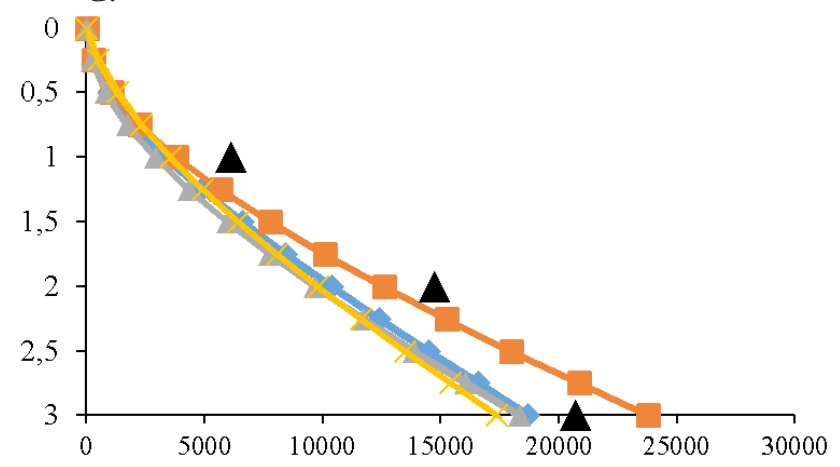

B.

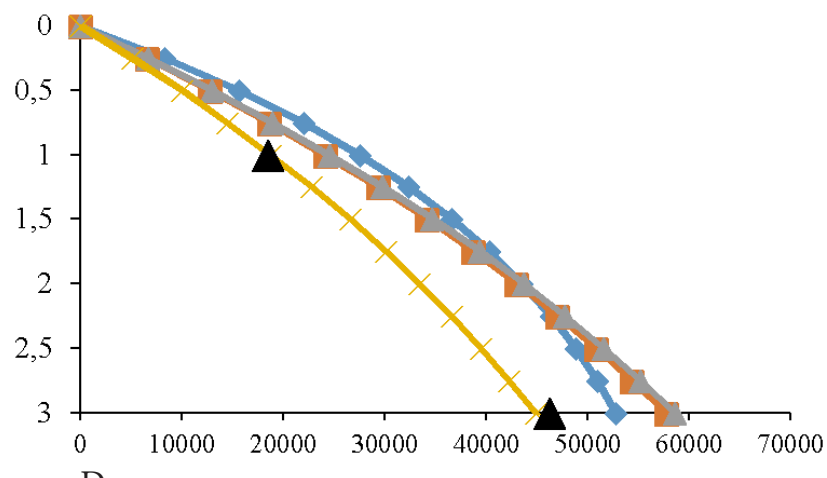

D.

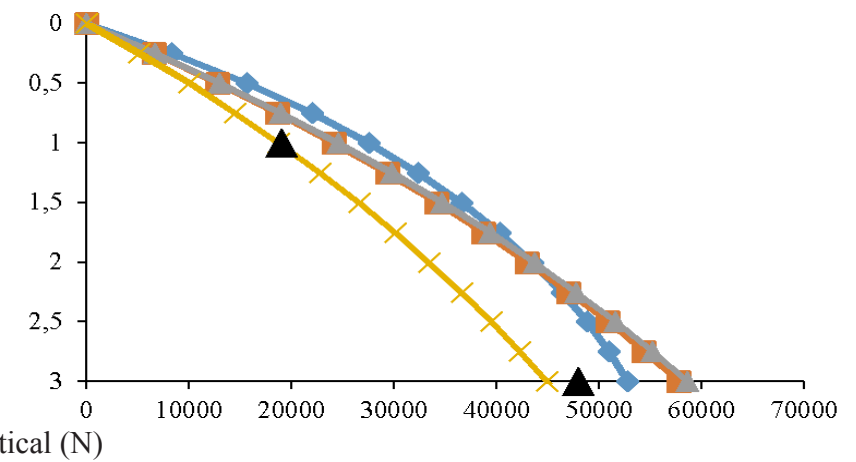

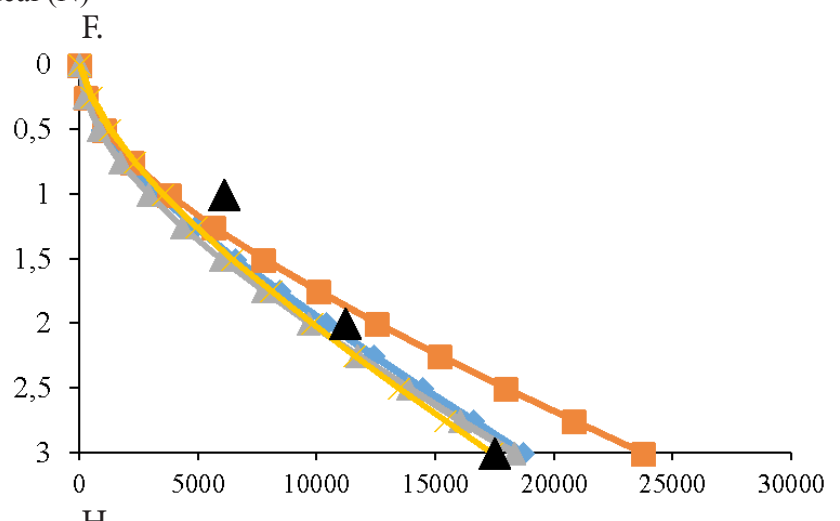

$\mathrm{H}$.

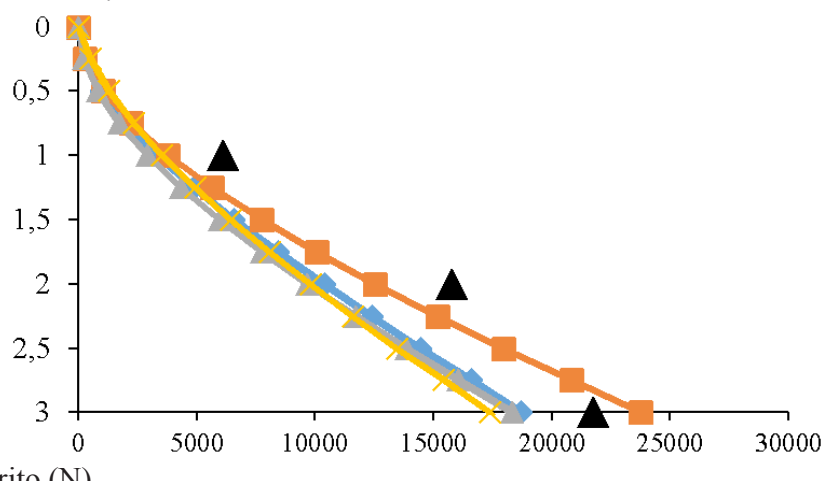

Força de atrito $(\mathrm{N})$

Figura 5. Forças verticais e de atrito nas descargas: (A) Forças verticais na descarga concêntrica pelo orifício D1, (B) Forças verticais na descarga excêntrica a 75\% pelo orifício D5, (C) Forças verticais na descarga múltipla a 50\% pelos orifícios D2 e D4, (D) Forças verticais na descarga múltipla a 75\% pelos orifícios D3 e D5, (E) Forças de atrito na descarga concêntrica pelo orifício D1; (F) Forças de atrito na descarga excêntrica a 75\% pelo orifício D3, (G) Forças de atrito na descarga múltipla a 50\% pelos orifícios D2 e D4, (H) Forças de atrito na descarga múltipla a 75\% pelos orifícios D3 e D5

pesquisa foi notada uma variação de $15 \%$ em relação ao estudo dos autores mencionados fato que pode ser justificado pela particularidade de cada ensaio, como dimensões do silo e tipo de produto armazenado.
Na Figura 5F, descarga excêntrica a 75\%, pode-se observar que todas as normas subestimaram os valores experimentais na profundidade de $1,00 \mathrm{~m}$ com uma diferença de até $48,8 \%$. Para a profundidade de 2,00 $\mathrm{m}$ esta diferença é reduzida para 
$10 \%$ chegando a se igualar aos valores experimentais na última profundidade.

Com exceção da profundidade de 1,00 m, a ISO 11697 (1995) resultou em valores superestimados, sobremaneira para a maior profundidade do silo, sendo $38 \%$ superior ao experimental. Para as demais normas os resultados quase não apresentam variação frente aos dados reais. Ressalta-se que os coeficientes de sobrecarga adotados para a descarga nessas normas, pouco diferem entre si, sendo recomendados 1,2 pela ISO 11607 (1995) e AS 3774 (1996), 1,15 pela Eurcode 1 (2006) e 1,1 na DIN 1055 (1987).

Segundo Palma \& Calil Júnior (2008) as normas resultam, na maioria das vezes, em valores superiores devido a fatores como formulação utilizada no cálculo do fator k, combinações com as propriedades físicas para obter os carregamentos máximos e adoção de pressões adicionais em alguns casos.

Nas Figuras $5 \mathrm{G}$ e $5 \mathrm{H}$ se encontram os resultados das teorias e dos ensaios para as descargas múltiplas a 50 e $75 \%$.

Observa-se que os valores experimentais se adequam à predição das normas apenas para a maior profundidade, ou seja, 3,00 m. Os maiores valores de força de atrito obtidos para as descargas múltiplas em comparação à descarga concêntrica e excêntrica se devem à formação de dois canais de fluxo de eixos simétricos e equidistantes no momento da descarga contribuindo para o aumento da quantidade de produto em contato com a parede neste momento, o que culminou em maior força de arrasto nas paredes.

\section{Conclusões}

1. Dentre as formulações propostas para o fator $\mathrm{k}$, a que mais se aproximou dos valores obtidos foi a teoria de Jaky (1948) com diferença de $17 \%$, mesmo seus valores sendo inferiores aos experimentais.

2. As forças verticais no fundo plano foram melhor representadas pela norma DIN 1055 (1987) para todas as situações de descarregamento.

3. Para as forças de atrito nas paredes, todas as normas apresentaram valores teóricos adequadamente próximos aos experimentais apenas para as profundidades de 2,00 e 3,00 m.

4. Quanto às descargas múltiplas, nenhuma das normas se mostrou adequada ao prever os valores nas profundidades de 1,00 e 2,00 m ficando apenas a norma ISO 11697 (1995) dentro dos valores obtidos experimentalmente para a profundidade máxima.

5. Em comparação à força de atrito no descarregamento concêntrico e excêntrico a $75 \%$, as descargas múltiplas produziram valores cerca de $30 \%$ superiores.

\section{Agradecimentos}

Os autores agradecem ao Grupo de Estudos em Silos (Silos) e ao Grupo de Estudos em Construções Rurais e Ambiência (GCAMB) da Universidade Federal de Campina Grande, pelo apoio em prol da realização desta pesquisa.

\section{Literatura Citada}

Aoki, R. Stresses of powders and granular materials in bins and hoppers. Theory and Applicated Mechanics, v.26, p.9-24, 1978.

AS 3774. Loads on bulk containers. Sydney: Australian Standard, 1996. 76p.

Cheung, A. B.; Calil Júnior, C. Modelo estocástico de pressões de produtos armazenados para a estimativa da confiabilidade estrutural de silos esbeltos. Caderno de Engenharia de Estruturas, v.11, p.1-22, 2009.

Couto, A.; Ruiz, A.; Aguado, P. J. Experimental study of the pressures exerted by wheat stored in slender cylindrical silos, varying the flow rate of material during discharge. Comparison with Eurocode 1 part 4. Powder Technology, v.237, p.450-467, 2013.

DIN 1055 - Design loads for buildings: Loads in silo bins. Berlin: 1987.6p.

Dogangun, A.; Karaca, Z.; Durmus, A.; Sezen, H. Cause of damage and failures in silo structures. Journal of Performance of Constructed Facilities, v.23, p.65-71, 2009.

Eurocode 1 Part 4. Actions on silos and tanks. Bruxelas: European Standard, 2006. 122p.

ISO 11697. Bases for design of structures: Loads due to bulk materials. Switzerland: International Standard, 1995. 18p.

Jaky, J. Pressure in silos. Soil Mechanics and Foundation Engineering, v.1. p.103-107, 1948.

Marques Neto, J. F. A.; Silva, M. C. A. T. Aplicação da alvenaria estrutural em sistemas de armazenamento de produtos agrícolas a granel. Engenharia Agrícola, v.31, p.201-210, 2011.

Nascimento, F. C; Calil Júnior, C. A relação entre as pressões horizontais e verticais em silos elevados: o parâmetro $\mathrm{k}$. Cadernos de Engenharia de Estruturas, v.11, p.17-37, 2009.

Palma, G.; Calil Júnior, C. Pressões e fluxo em silos esbeltos $(\mathrm{H} / \mathrm{D} \geq 1,5)$. Caderno de Engenharia de Estruturas, v.10, p.129-150, 2008.

Ramírez, A.; Nielsen, J.; Ayuga, F. Pressure measurements in steel silos with eccentric hoppers. Powder Technology, v.201, p.7-20, 2010.

Ruiz, A.; Couto, A.; Aguado, P. J. Design and instrumentation of a mid-size test station for measuring static and dynamic pressures in silos under different conditions - Part II: Construction and validation. Computers and Electronics in Agriculture, v.85, p. 174-187, 2012.

Sadowski, A. J.; Rotter, J. M. Steel silos with different aspect ratios: I - behavior under concentric discharge. Journal of Constructional Steel Research, v.67, p.1537-1544, 2011.

Walker, D. M. An approximate theory for pressures and arching in hoppers. Chemical Engineering Science, v.21, p.975-997, 1966.

Wójcika, M.; Tejchman, J.; Enstad, G. G. Confined granular flow in silos with inserts - Full-scale experiments. Powder Technology, v.222, p.15-36, 2012. 